\title{
Electrospun Poly Lactic Acid (PLA) Fibres: Effect of Different Solvent Systems on Fibre Morphology and Diameter
}

\author{
R. Casasola ${ }^{a}$, N. L. Thomas ${ }^{b}$, A. Trybala ${ }^{a}$, S. Georgiadou ${ }^{a^{*}}$ \\ ${ }^{a}$ Department of Chemical Engineering, Loughborough University, Loughborough, Leicestershire, \\ LE11 3TU, UK \\ ${ }^{b}$ Materials Department, Loughborough University, Loughborough, Leicestershire, LE11 3TU, UK \\ * Corresponding author. Tel: +44 (0)1509 222521 \\ E-mail addresses: $\underline{\text { S.Georgiadou@lboro.ac.uk, R.Casasola@,lboro.ac.uk }}$
}

\begin{abstract}
The selection of an appropriate non-hazardous solvent or solvent system is essential to determine the rheological properties and electrospinnability of the solution, the productivity, and the morphology of nanofibres. In this study, poly lactic acid (PLA) solutions were prepared in various pure solvents and binary-solvent systems to investigate the effect of different solution properties on nanofibre morphology and diameter. Viscosity, conductivity and surface tension of each solution were measured. Nanofibre morphology was observed by scanning electron microscopy (SEM). Of all the solvent systems used acetone/dimethylformamide gave the highest fibre productivity and finest defect-free nanofibres. Therefore this solvent system was studied in more detail, varying the solvent ratio. Also the polymer concentration in this solvent system was varied to investigate the effect on nanofibre morphology and solution properties. Morphological investigations were done in correlation with rheological measurements: beaded nanofibrous structures were collected from solutions with concentration around the critical chain entanglement concentration $\left(C_{e}\right)$, while defect-free nanofibres were produced when the concentration was increased to about twice the entanglement concentration. Further investigation of the effect of the PLA concentration on the elastic $\left(G^{\prime}\right)$ and the plastic $\left(G^{\prime}\right.$ ') moduli showed a sudden increase of the elastic moduli $\left(G^{\prime}\right)$ at the critical chain entanglement concentration. The results showed that the solvent properties, boiling point, viscosity, conductivity and surface tension, have a significant effect on process productivity, morphology and diameter distribution of the PLA nanofibres.
\end{abstract}

Keywords: electrospinning, poly lactic acid, nanofibres, chain entanglements, elastic modulus. 


\section{Introduction}

Electrospun nanofibres have shown significant potential in a number of applications such as filtration systems [1], chemical and optical sensors [2], tissue engineering [3-5], wound healing [6] and release of drugs [7], due to their high surface area to volume ratio, small pore size and high porosity. The electrospinning process relies on the application of an electric field [8] between a needle-tipped syringe containing the polymeric solution and a collector for the deposition of nanofibres. Therefore the polymeric solution is electrically charged and a conical droplet is formed at the needle tip. As the electric forces overcome the surface tension of the solution, a polymeric jet is generated from the surface of the droplet and travels towards the collector. Between the needle and the collector, the solvent evaporates from the jet and consequently nanofibres can be collected [9]. The morphology and diameter of the resultant nanofibres depend on many parameters. These have been divided into three groups: solution properties, process parameters and ambient conditions [10-12]. The optimization of these parameters is significant in order to obtain continuous nanofibres with specific morphology and well-defined physical and mechanical properties, depending on the type of application. The majority of the literature so far has dealt with the study of the process parameters, whereas the effects of the solution properties on the electrospinning mechanism have not been fully understood and determined yet. The selection of the solvent or mixedsolvent system to dissolve the polymer is one of the main factors influencing the solution properties and consequently the electrospinnability of the solution. It has been shown that polymer concentration, conductivity and surface tension of the solution all have an important effect on the fibre morphology and diameter [13].

Wannatong et al. [14] investigated the effect of solvent properties on the productivity and morphology of polystyrene (PS) nanofibres. They found that the diameter of PS fibres decreased with increasing density and boiling point and that a large difference between the solubility parameters of the solvent and the polymer was responsible for bead-string morphology. Moreover nanofibre productivity increased with increasing dielectric constant and dipole moment of the solvents.

Lee et al [15] studied the effect of different solvent systems on poly (caprolactone) (PCL) nanofibres. Only methylene chloride (MC) was able to dissolve the polymer. However electrospinning of the solution often stopped due to the low boiling point of MC. Addition of dimethylformamide (DMF) to MC enhanced the electrospinning process and allowed the production of smaller nanofibres. It was suggested that nanofibres could be collected because DMF decreased the viscosity and increased the electrical conductivity of the PCL solution. In a following study Lee et al [16] found similar results on the electrospinning of poly (vinyl chloride) PVC using tetrahydrofuran (THF) and dimethylformamide (DMF). On increasing DMF in the THF/DMF solution, smaller nanofibres could be collected. DMF showed polyelectrolyte behaviour despite being a poor solvent for PVC in comparison with THF [16]. 
Regarding the production of PLA nanofibres, the effects of polymer concentration and process parameters, such as electric field, feed rate and distance between needle and collector, on nanofibre morphology have been investigated. $\mathrm{Gu}$ and Ren [17] dissolved amorphous PLA (PDLA) in a mixture of chloroform (CHL) and acetone (AC) $(2 / 1 \mathrm{v} / \mathrm{v})$ and experimental design (DOE) was used to optimize and predict the morphology and mean diameter of PLA nanofibres. Concentration and applied voltage were the factors varied in the different experiments. It was concluded that polymer concentration plays an important role in determining the nanofibre diameter. Fibres with more uniform diameter were obtained at higher concentrations and higher applied voltage. Similarly Patra et al [18] used experimental design to establish a desirable set of conditions to produce electrospun PLLA nanofibres. They dissolved crystalline PLA (PLLA) $\left(\mathrm{M}_{\mathrm{w}}=104 \mathrm{kDa}\right)$ in dichloromethane (DCM) and dimethylformamide $(\mathrm{DMF})$ at a ratio of $60 / 40 \mathrm{v} / \mathrm{v}$. The factors chosen were concentration, voltage, feed rate and needle-collector distance. Low polymer concentration $(4 \% \mathrm{w} / \mathrm{v})$ and high applied voltage $(10 \mathrm{kV})$ appeared to be the best choice to get the finest diameter. However many beads were also collected.

Yang et al [19] dissolved PLLA $\left(\mathrm{M}_{\mathrm{w}}=300 \mathrm{kDa}\right)$ in DCM/DMF $(70 / 30 \mathrm{v} / \mathrm{v})$ at a concentration of $1 \%(\mathrm{w} / \mathrm{w})$ and collected nanofibres with average diameter of $272 \pm 77 \mathrm{~nm}$. In another study Prabhakaran et al [20] produced PLLA nanofibres with a diameter of $860 \pm 110 \mathrm{~nm}\left(\mathrm{M}_{\mathrm{w}}\right.$ $\mathrm{PLA}=100 \mathrm{kDa}$ ) from a hexafluoroisopropanol (HFIP) solution $16 \%(\mathrm{w} / \mathrm{v})$, On the other hand, Ishii et al [21] dissolved PLLA $\left(\mathrm{M}_{\mathrm{w}}=850 \mathrm{kDa}\right)$ in HFIP at a concentration of $1 \mathrm{wt} . \%$ and produced nanofibre with a mean diameter of $300 \mathrm{~nm}$. This shows that molecular weight is another important variable.

Therefore the optimization of the electrospinning process for the production of homogeneous nanofibrous mats involves the selection of an appropriate solvent or solvent system depending on the type of polymer [22-24]. Generally PLA (amorphous PDLA or crystalline PLLA) is dissolved in chlorinated and fluorinated solvents. However a low toxicity solvent system would be preferable when nanofibrous mats are produced for applications in tissue engineering to avoid any adverse reactions with cells.

Another parameter that has a significant influence on fibre formation during the electrospinning of polymeric solutions is the number of chain entanglements in the solution. Experimental observations have shown that a minimum level of chain entanglements, and therefore a minimum concentration, is required for the production of continuous fibres $[25,26]$. A number of studies have shown that a minimum polymer concentration, known as the entanglement concentration $\left(C_{e}\right)$, is required for beaded fibre formation [27-29]. Below $\mathrm{C}_{\mathrm{e}}$ only droplets of the polymeric solution are collected because there are no entanglements. Above $\mathrm{C}_{\mathrm{e}}$ fibres with beads start to be collected. On further increasing the polymer concentration, the frequency of bead formation decreases. However at high concentration, no fibres are produced due to the high solution viscosity [15,30]. It has been reported $[24,30]$ that there are four different concentration regimes for polymer dissolved in a good solvent: 
dilute, semi dilute unentangled, semi dilute entangled and concentrated. In the dilute regime the polymer chains are separated by the solvent molecules, and therefore in the electrospinning process only polymer droplets can be collected. At the overlap concentration $\mathrm{C}^{*}$ the chains overlap each other but the concentration is not high enough to cause any significant degree of entanglement. The entanglement concentration $\mathrm{C}_{\mathrm{e}}$ represents the transition between the semi dilute unentangled and the semi dilute entangled. Then when $\mathrm{C}>$ $\mathrm{C}_{\mathrm{e}}$ uniform beaded nanofibres can be collected. It has been reported that generally bead-free nanofibres could be produced when the concentration is 2-2.5 times $C_{e}[25,31,32]$.

For example Colby and his co-workers [26] have shown that for a linear polymer in a good solvent, the specific viscosity $\eta_{\mathrm{sp}}$ is proportional to $\mathrm{C}^{1.25}$ in the semi dilute unentangled regime and $\eta_{\mathrm{sp}} \sim \mathrm{C}^{4.25-4.5}$ in the semi dilute entangled regime. Similarly Chisca et al [28] investigated the role of chain entanglements in polyimide solutions. They found that the specific viscosity dependence on concentration changes from $\mathrm{C}^{1.11}$ to $\mathrm{C}^{4.42}$ at a concentration, $\mathrm{C}_{\mathrm{e}}$, of $18.3 \%$ and this is the critical entanglement concentration. Approximately double the value of $\mathrm{C}_{\mathrm{e}}, 30 \%$, was the minimum concentration required for electrospinning of defect-free nanofibres as shown from SEM images.

Linear and branched polyesters with different molecular weight were investigated by McKee et al [25]. They showed that the unentangled regime $\eta_{\mathrm{sp}} \sim \mathrm{C}^{1.39}$ was in good agreement with the previous work $\left(\eta_{\mathrm{sp}} \sim \mathrm{C}^{1.25}\right)$. In the entangled regime, the specific viscosity was expected to scale with the polymer concentration to approximately the 4.5 power. However, a much weaker dependence was observed in the entangled regime $\left(\eta_{\mathrm{sp}} \sim \mathrm{C}^{2.7}\right)$, which was attributed to the branched architecture of the PET-co-PEI copolymers.

Although the effect of the polymer concentration on the zero shear viscosity has been investigated, the role of elasticity of the polymer solutions on nanofibre morphology is rarely considered. A few studies have been showed the effect of the elastic ( $\left.G^{\prime}\right)$ and plastic modulus $(G$ ") of the polymer solution on the electrospinning process [28,33]. For a successful electrospinning the plasticity $G^{\prime}$ ' of the solution has to dominate over the elasticity (G') $[34,35]$. However the elasticity of the solution has to be low but still present due to the fact that the increased elastic force increases the tendency of the jet to contract [33]. A higher degree of elasticity is observed to suppress the breakup of the jet into droplets by the Rayleigh instability and therefore to allow the production of nanofibres. Correlations between rheological parameters of polymer solutions and the electrospinnability of the solutions and the resultant nanofibre morphology are required to understand the mechanisms underlying jet stabilization.

The main objectives of this study were to produce PLA nanofibres using lower toxicity solvent systems, to identify a relationship between chain entanglements and solution electrospinnability and to investigate the effect of solution properties on the morphology, mean diameter and diameter distribution diameter of PLA nanofibres. The most promising solvent system was studied in more detail and solution viscosity, surface tension and conductivity were measured. The dependence of viscosity on concentration was investigated 
and the entanglement concentration $\mathrm{C}_{\mathrm{e}}$ was identified and related to the observed nanofibre morphology. The effect of PLA concentration on $G^{\prime}$ and $G^{\prime}$ ' and their relationship to the solution electrospinnability were also examined.

\section{Materials and methods}

\subsection{Materials}

Poly (lactic acid) (PLA 4060D) was obtained from Nature Works LLC. 4060D is an amorphous polymer with an L-lactide content of around 88 weight $\%$ and with a glass transition temperature $\left(\mathrm{T}_{\mathrm{g}}\right)$ of $55-60^{\circ} \mathrm{C}$ [36,37]. All solvents were supplied by Fischer Scientific and used without further purification. The solvents used in this study were: acetone (AC), 1,4-dioxane (DX), tetrahydrofuran (THF), dichloromethane (DCM), chloroform (CHL), dimethylformamide (DMF) and dimethylacetamide (DMAc). Table 1 shows some properties of the selected solvents, which were chosen on the basis that their solubility parameters are close to the solubility parameter of PLA (which is $10 \mathrm{cal}^{1 / 2} \cdot \mathrm{cm}^{-3 / 2}$ )[38].

\subsection{Preparation of PLA solutions}

The polymer solutions for electrospinning were prepared by dissolving PLA in single solvents and binary-solvent systems of acetone and another solvent $(50 / 50 \mathrm{v} / \mathrm{v})$ to obtain a $10 \%$ $\mathrm{w} / \mathrm{v}$ polymer concentration. For the preparation of all solutions, the solvents were added to a pre-weighted amount of polymer in a glass bottle. All solutions were magnetically stirred at room temperature $\left(20-22^{\circ} \mathrm{C}\right)$ for 4 hours, until complete dissolution of the polymer. The most promising solvent system was then studied in more detail. The effect of the polymer concentration on nanofibre morphology in this solvent system was investigated: PLA was dissolved to obtain solutions with concentrations $5,7.5,10,12.5$ and $15 \% \mathrm{w} / \mathrm{v}$.

\subsection{Electrospinning process}

A high voltage power supply was used to generate an electric field of $20 \mathrm{kV}$ between a collector and a needle. The polymer solution was placed in a 20-ml plastic syringe (Luer lock syringe, Sigma Aldrich) and a pump system (PHD ULTRA ${ }^{\mathrm{TM}}$, Harvard Apparatus) was used to feed a constant solution $(1.0 \mathrm{ml} / \mathrm{h})$ through the needle. A polyethylene capillary tube was used to connect the syringe and the needle (inner diameter $0.6 \mathrm{~mm}$ ) which was set up vertically. The collector was a rectangular copper plate covered with aluminium foil and located $15 \mathrm{~cm}$ from the needle tip for the deposition of nanofibres. The spinning time for each solution was fixed at 10 minutes. The electrospinning experiments were performed at room temperature $\left(\sim 20^{\circ} \mathrm{C}\right)$. Three nanofibre samples were prepared for each solution. 


\subsection{Characterisation of PLA solutions}

The rheological properties of the PLA solutions were measured with a HAAKE VT550 rheometer equipped with a cone-plate measuring system (cone radius $40 \mathrm{~mm}$, cone angle 1.59 degrees, truncation $56 \mu \mathrm{m})$ at constant temperature $\left(25^{\circ} \mathrm{C}\right)$. Two types of rheological measurements were performed. The rotational tests were used to determine the solution viscosity, while the oscillatory test was used to define the storage $\left(G^{\prime}\right)$ and loss $\left(G^{\prime}\right.$ ') modulus of the solutions. The shear rate during the rotational tests ranged from 0.1 to $400 \mathrm{~s}^{-1}$, while the oscillatory measurements were performed at a shear stress of $0.5 \mathrm{~Pa}$ between frequencies of 0.1 and $100 \mathrm{~Hz}$. All measurements were repeated three times for each solution. The viscosity values are taken at a shear rate of $1 \mathrm{~s}^{-1}$, while the results of G' and G', are at a frequency of $0.5,1$ and $2 \mathrm{~Hz}$.

The surface tension of the PLA solutions was measured using a surface tension meter (White Electric Instrument, DB2kS). Five measurements were taken for each solution. The electrical conductivity of the polymer solutions was determined using a conductivity meter (Jenway Model 470) with a cell constant $K=1.07$ and accuracy of $\pm 0.5 \%$.

\subsection{Electrospun Fibre Analysis}

The morphology of electrospun PLA nanofibres was characterized by field emission scanning electron microscopy (FEG-SEM, LEO 1530VP) using an accelerating voltage of $5.0 \mathrm{kV}$. Before observation, each sample was coated using a gold/palladium sputter coater for 2 minutes (SC7640, Emitech). The diameter of PLA nanofibres was measured using image software (AxioVision Rel 4.8). 150 measurements for each sample were made to determine the mean nanofibre diameter.

\section{Results and discussion}

\section{Single-solvent systems}

Poly lactic acid (PLA) dissolved in all solvents within 3-4 hours. Figure 1 shows scanning electron micrographs of the samples produced from electrospinning. Of all the solvents, only acetone (AC) was found to produce a sufficient quantity of fibres to form a nanofibre mat, possibly due to its relatively high conductivity and dielectric constant compared to the other single solvents, combined with relatively low surface tension. These nanofibres show bead string morphology with a mean nanofibre diameter of $757 \mathrm{~nm}$, as shown in figure 1 (a). 1,4dioxane (DX) and tetrahydrofuran (THF) did not produce continuous nanofibres, but droplets were collected (Figure 1(b) and 1(c)), probably due to their high surface tension and low conductivity. The coexistence of few nanofibres with many droplets was observed in electrospun samples produced from dichloromethane (DCM) and chloroform (CHL) Figures 1(c) and 1(d). Despite the higher dielectric constants of dimethylformamide (DMF) 
and dimethylacetamide (DMAc), nanofibres could not be produced: only droplets were collected as shown in Figures 1(f) and 1(g). A possible explanation could be the high boiling point of DMF and DMAc as shown in Table 1, so that the polymeric jet did not have enough time to dry completely during its flight to the collector. It is well known that the range of concentrations from which continuous fibres can be obtained strongly depends from the type of polymer/solvent system.
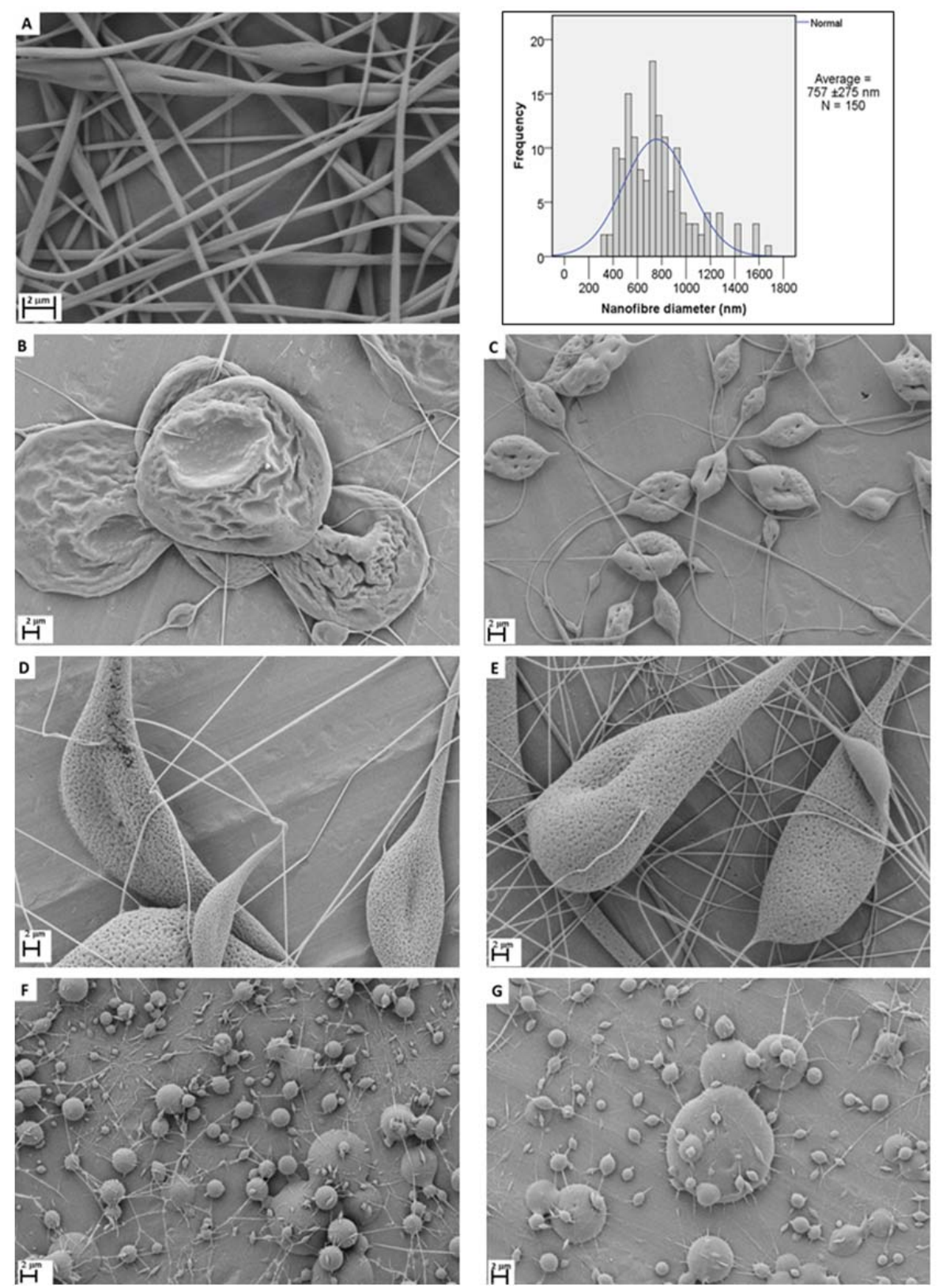

Figure 1. Effect of single solvent systems on nanofibre morphology: scanning electron micrographs of PLA nanofibres from solutions of $10 \%(\mathrm{w} / \mathrm{v})$ of PLA in: (a) acetone $(10000 \mathrm{x})$ with nanofibre diameter distribution, (b) 1,4-dioxane (5000x), (c) tetrahydrofuran (5000x), (d) dichloromethane (5000x), (e) chloroform (5000x), (f) dimethylformamide (5000x) and (g) dimethylacetamide (5000x) 
Table 1. Properties of the solvents used in this study ( $\eta$ is the viscosity, $\varepsilon$ is the dielectric constant, $\sigma$ is the surface tension, $\delta$ is the solubility parameter) (Smallwood I. Handbook of organic solvent properties, Halsted Press, London 1996).

\begin{tabular}{|l|c|c|c|c|c|c|}
\hline Solvent & $\begin{array}{c}\text { Boiling point } \\
{ }^{\mathbf{C}}\end{array}$ & $\begin{array}{c}\boldsymbol{\eta} \\
\mathbf{m P a} \cdot \mathbf{s}\end{array}$ & $\begin{array}{c}\text { Electrical } \\
\mathbf{c o n d u c t i v i t y} \\
\boldsymbol{\mu S} \cdot \mathbf{c m}^{-1}\end{array}$ & $\boldsymbol{\varepsilon}$ & $\begin{array}{c}\boldsymbol{\sigma} \\
\mathbf{m N} / \mathbf{m}\end{array}$ & $\begin{array}{c}\boldsymbol{\delta} \\
\mathbf{c a l}^{1 / 2} \cdot \mathbf{c m}^{-3 / 2}\end{array}$ \\
\hline Acetone - AC & 56 & 0.308 & 0.20 & 20.60 & 23.3 & 10 \\
\hline $1,4-$ Dioxane - DX & 101 & 1.177 & $5.0 \mathrm{E}-09$ & 2.21 & 40.0 & 10 \\
\hline Tetrahydrofuran - THF & 66 & 0.480 & $4.5 \mathrm{E}+01$ & 7.60 & 28.0 & 9.1 \\
\hline $\begin{array}{l}\text { Dichloromethane - } \\
\text { DCM }\end{array}$ & 40 & 0.449 & $4.30 \mathrm{E}-05$ & 9.10 & 28.1 & 9.7 \\
\hline Chloroform - CHL & 61 & 0.563 & $1.0 \mathrm{E}-04$ & 4.80 & 27.2 & 9.3 \\
\hline $\begin{array}{l}\text { Dimethylformamide - } \\
\text { DMF }\end{array}$ & 153 & 0.920 & $6.0 \mathrm{E}-02$ & 36.70 & 35.0 & 12.1 \\
\hline $\begin{array}{l}\text { Dimethylacetamide - } \\
\text { DMAc }\end{array}$ & 166 & 1.960 & $/$ & 37.80 & 43.7 & 11.0 \\
\hline
\end{tabular}

\section{Binary-solvent systems}

Addition of acetone to the other solvents (at a of ratio 50/50 v/v) enabled the production of nanofibres as shown in Figure 2. Nanofibres with bead-string morphology were found using the solvent systems AC/DX, AC/THF, AC/DCM and AC/CHL as shown in Figures 2(a), 2(b), 2(c) and 2(d), respectively. Smooth defect-free nanofibres with a narrow diameter distribution were collected using the solvent systems acetone/dimethylformamide and acetone/dimethylacetamide, as shown in Figures 2(e) and 2(f). It was found that the nanofibre diameter decreases as the boiling point of the second solvent in the mixed-solvent system increases as shown in Figure 3. Wannatong et al [14] found a similar correlation between boiling point of the solvent and fibre diameter for the electrospinning of poly(styrene) in $\mathrm{m}$ cresol, toluene, dimethylformamide and tetrahydrofuran. Solvents with higher boiling point evaporate slower from the ejected charged jet causing the viscoelastic properties of the jet to change and therefore the stretching of the jet to a much lower diameter. Figure 2(c) and 2(d) shows that the rapid evaporations have led to porous appearance of nanofibres collected from $\mathrm{AC} / \mathrm{DCM}$ and AC/CHL. The acetone/dimethylformamide solution produced nanofibres with the thinnest diameter $(210 \mathrm{~nm})$, as shown in Table 2. Most likely the high solution conductivity leads to the increase of surface charge of spinning jet, stronger elongation forces are imposed to the jet, resulting in defect-free, uniform nanofibres with a narrow diameter distribution (small standard deviation). However these nanofibres were not completely dried when they reached the collector probably due to the high boiling point of DMF. 

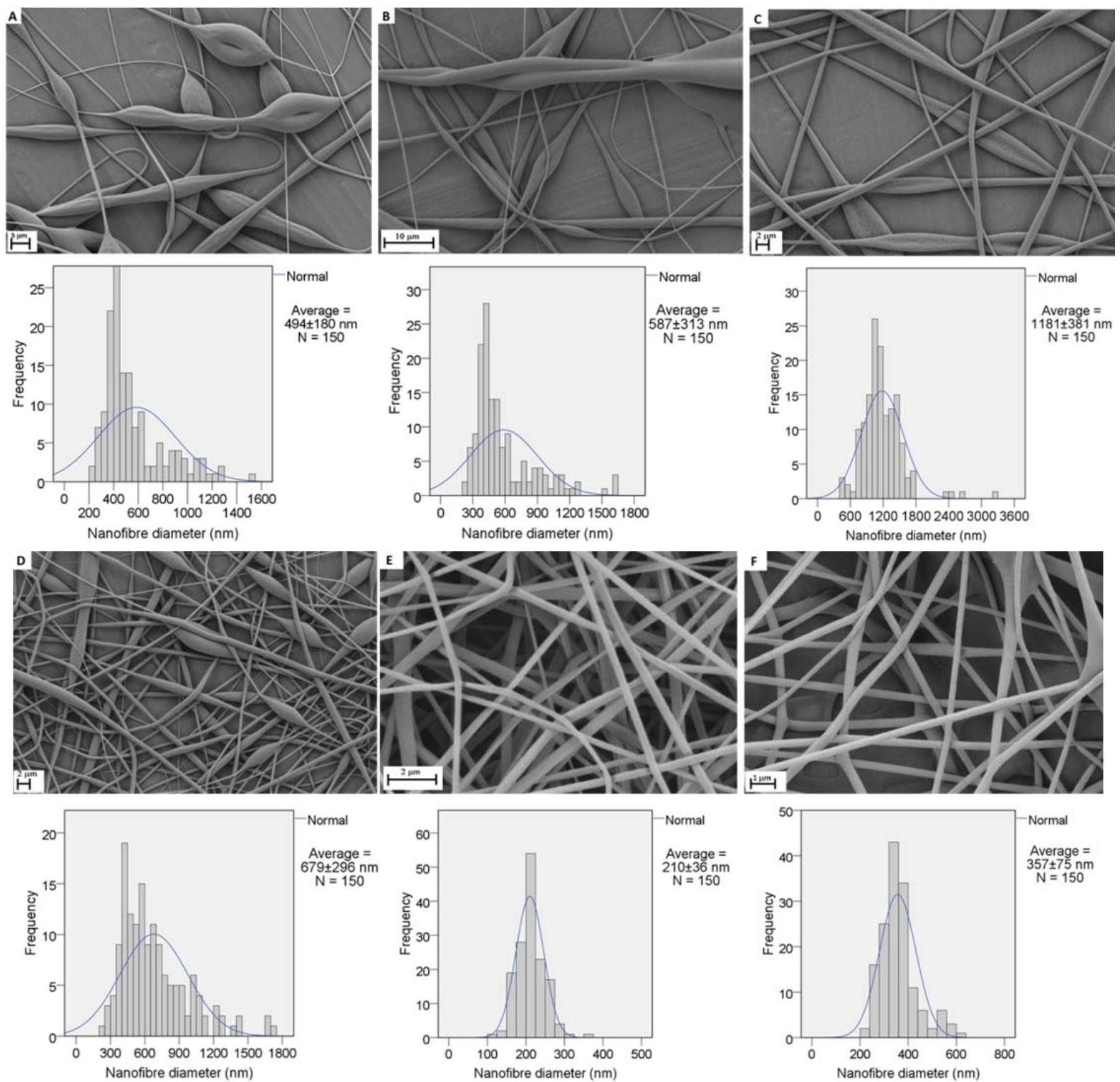

Figure 2. Effect of binary-solvent systems on nanofibre morphology: scanning electron micrographs of PLA nanofibres with nanofibre diameter distribution from solutions of $10 \%(w / v)$ of PLA in (a) acetone/1,4-dioxane (5000x), (b) acetone/tetrahydrofuran (4000x), (c) acetone/dichloromethane (5000x), (d) acetone/chloroform (5000x) (e) acetone/dimethylformamide (20000x) and (f) acetone/dimethylacetamide (20000x) 
Table 2. PLA solution properties. Physical properties of $10 \% \mathrm{w} / \mathrm{v}$ PLA solution in single and binary-solvent systems ( ${ }^{a}$ ratio 50/50 v/v for binary-solvent systems) and mean diameter of nanofibres produced by the electrospinning process

\begin{tabular}{|c|c|c|c|c|}
\hline Solvent system & $\begin{array}{c}\text { Viscosity } \\
\mathrm{mPa} \cdot \mathbf{s}\end{array}$ & $\begin{array}{c}\text { Surface tension } \\
\qquad \mathbf{m N} \cdot \mathbf{m}^{-1}\end{array}$ & $\begin{array}{c}\text { Conductivity } \\
\mu \mathrm{S} \cdot \mathbf{c m}^{-1}\end{array}$ & $\begin{array}{c}\text { Morphology and mean } \\
\text { nanofibre diameter } \\
\text { nm }\end{array}$ \\
\hline $\mathrm{AC}$ & $102 \pm 10$ & $25.5 \pm 0.9$ & 1.30 & $757 \pm 275$ \\
\hline $\mathrm{DX}$ & $531 \pm 26$ & $36.8 \pm 1.3$ & 0.03 & No nanofibres \\
\hline THF & $280 \pm 31$ & $30.4 \pm 1.0$ & 0.01 & No nanofibres \\
\hline DCM & $167 \pm 67$ & $30.2 \pm 0.9$ & 0.04 & No nanofibres \\
\hline CHL & $372 \pm 47$ & $31.0 \pm 0.6$ & 0.01 & No nanofibres \\
\hline $\mathrm{DMF}$ & $155 \pm 9$ & $38.3 \pm 1.3$ & 4.0 & No nanofibres \\
\hline DMAc & $210 \pm 21$ & $37.7 \pm 1.0$ & 2.69 & No nanofibres \\
\hline $\mathrm{AC} / \mathrm{DX}^{\mathrm{a}}$ & $305 \pm 15$ & $30.1 \pm 0.7$ & 0.17 & Beaded fibres, $494 \pm 180$ \\
\hline $\mathrm{AC} / \mathrm{THF}^{\mathrm{a}}$ & $221 \pm 14$ & $26.9 \pm 0.9$ & 0.40 & Beaded fibres, $587 \pm 313$ \\
\hline $\mathrm{AC} / \mathrm{DCM}^{\mathrm{a}}$ & $133 \pm 64$ & $27.6 \pm 1.2$ & 0.62 & Beaded fibres, $1181 \pm 381$ \\
\hline $\mathrm{AC} / \mathrm{CHL}^{\mathrm{a}}$ & $169 \pm 15$ & $27.3 \pm 0.7$ & 0.65 & Beaded fibres , $679 \pm 296$ \\
\hline $\mathrm{AC} / \mathrm{DMF}^{\mathrm{a}}$ & $252 \pm 53$ & $30.6 \pm 0.8$ & 2.80 & Defect-free fibres, $210 \pm 36$ \\
\hline $\mathrm{AC} / \mathrm{DMAc}^{\mathrm{a}}$ & $296 \pm 47$ & $29.4 \pm 1.5$ & 3.22 & Defect-free fibres, $357 \pm 75$ \\
\hline
\end{tabular}

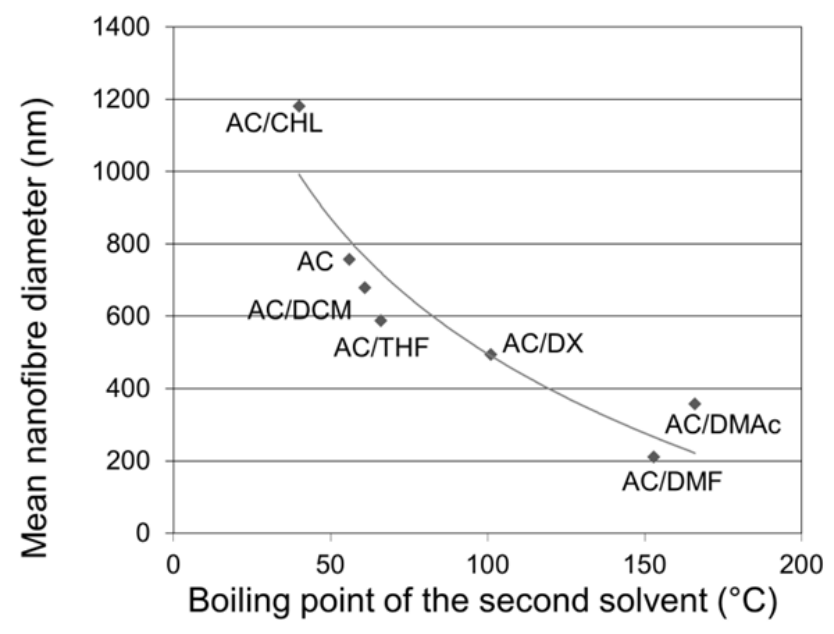

Figure 3. Effect of the boiling point of the second solvent in binary solvent systems on mean nanofibre diameter (acetone, AC; dichloromethane, DCM; chloroform, CHL; 1,4-dioxane, DX; tetrahydrofuran, THF; dimethylformamide, DMF; dimethylacetamide, DMAc) 
Regarding the nanofibre diameter distribution, it was noticed that more homogenous samples with low standard deviation of diameter from the mean value where produced using the PLA solutions in $\mathrm{AC} / \mathrm{DMF}$ and $\mathrm{AC} / \mathrm{DMAc}$, most likely due to the higher dielectric constant of the second solvent (DMF, DMAc). Poly lactic acid solutions of AC/DCM and AC/CHL showed lower solution conductivity resulting in the production of nanofibres with bigger diameter and wide diameter distribution, as shown in Figure 2.

\section{Effect of solvent ratio - acetone/dimethylformamide (AC/DMF)}

Of all the mixed solvent systems used to electrospin the $10 \% \mathrm{w} / \mathrm{v}$ PLA solution, acetone/dimethylformamide was found to produce defect-free nanofibres with the smallest mean diameter and a narrow diameter distribution. Therefore acetone and dimethylformamide were mixed in a range of compositional ratios (20:80, 40:60, 60:40, and $80: 20 \mathrm{v} / \mathrm{v}$ ) and the effect on the resultant PLA nanofibre morphology was studied.

Figure 4 shows selected SEM images of the nanofibres collected. The ratios 20/80 and 40/60 (Figure 4(a) and 4(b)) did not allow the production of nanofibres and neither did the pure solvent DMF. Only beads were collected. Some of the solution properties, i.e. viscosity, surface tension, and conductivity, of the PLA solutions were measured and are reported in Table 3 with the corresponding mean diameter of the collected nanofibres. The smallest and most uniform defect-free nanofibres were produced using the ratio $60 / 40 \mathrm{v} / \mathrm{v}$. The previous results showed that the solvent system $\mathrm{AC} / \mathrm{DMF}$ at a ratio of $50 / 50 \mathrm{v} / \mathrm{v}$ produced defect-free nanofibres with smaller mean diameter $(210 \mathrm{~nm})$. A possible explanation for this discrepancy could be a slight difference in ambient conditions as temperature and humidity may influence the morphology of the resultant nanofibres $[11,39]$.

Most likely the higher surface tension of the PLA solutions at AC/DMF ratios of 20/80 and 40/60 inhibits nanofibre formation (Table 3). Nanofibres were firstly produced when using a ratio of $50 / 50 \mathrm{v} / \mathrm{v}$. The observed increase in the fibre diameter with increasing amount of acetone in the mixed solvent system may be a result of higher solution viscosity and lower conductivity resulting in an increase in the viscoelastic force and a reduction in the Coulomb repulsive force. Figure 5 shows the effect of the solvent ratio on the solution viscosity and surface tension. Regarding the nanofibre diameter distribution, increasing amount of acetone leads to bigger nanofibres and higher standard deviation from the mean diameter. It is very difficult to separate the effect of viscosity, conductivity and surface tension on the resultant nanofibre morphology and diameter.

It is reported that increasing solution conductivity or charge density allows the production of thinner and more uniform fibres with fewer defects [40,41]. The solution is exposed to greater tensile force with the application of an electric field and therefore the polymeric jet is subjected to greater elongation. The surface tension is the parameter in competition with the viscosity of the solution. Reducing the surface tension enables the production of nanofibres with fewer beads. In fact, on increasing the surface tension, the jet becomes unstable and 
more beads appear on the nanofibre mats $[13,42]$. Nevertheless, the application of a lower surface tension to get bead-free nanofibres is not a general rule, but depends on the type of solvent $[13,43]$.

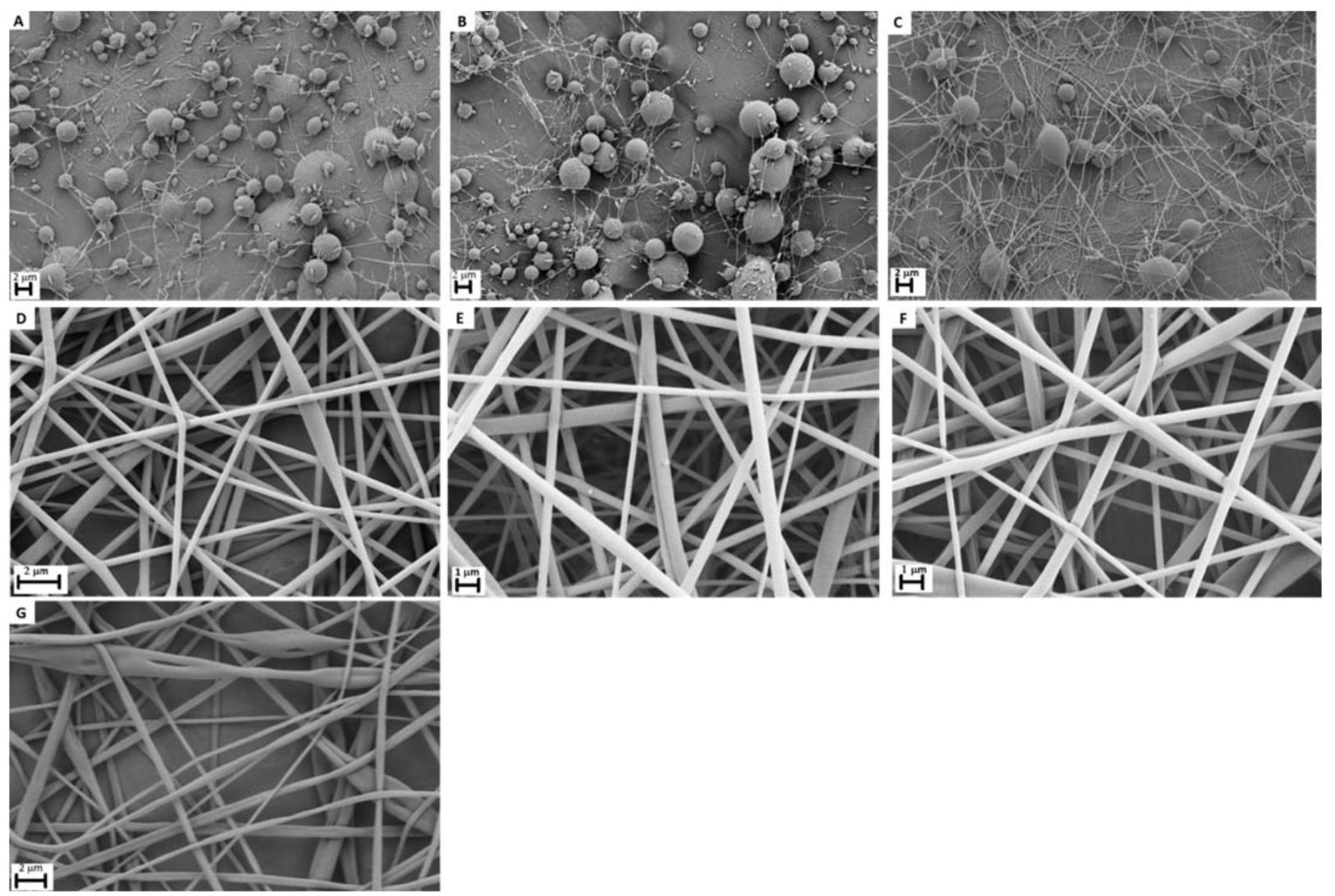

Figure 4. Effect of solvent ratio (AC/DMF) on nanofibre morphology: scanning electron micrographs of PLA nanofibres from solutions of $10 \%(\mathrm{w} / \mathrm{v})$ of PLA in acetone/dimethylformamide at a ratio of (v/v) (a) 0/100 (5000x), (b) 20/80 (5000x), (c) 40/60 (5000x), (d) 50/50 (15000x), (e) 60/40 (15000x) (f) $80 / 20(15000 x),(g) 100 / 0(10000 x)$

Table 3. Effect of solvent ratio (AC/DMF) - Physical solution properties for $10 \% \mathrm{w} / \mathrm{v}$ PLA solution in different solvent ratios acetone/dimethylformamide and mean diameter of nanofibres produced by the electrospinning process

\begin{tabular}{|c|c|c|c|c|}
\hline $\begin{array}{c}\text { AC/DMF } \\
\mathbf{v} / \mathbf{v}\end{array}$ & $\begin{array}{c}\text { Viscosity } \\
\mathbf{m P a} \cdot \mathbf{s}\end{array}$ & $\begin{array}{c}\text { Surface } \\
\text { tension } \\
\mathbf{m N} \cdot \mathbf{m}^{-\mathbf{1}}\end{array}$ & $\begin{array}{c}\text { Conductivity } \\
\boldsymbol{\mu S} \cdot \mathbf{c m}^{-\mathbf{1}}\end{array}$ & $\begin{array}{c}\text { Mean } \\
\text { nanofibre } \\
\text { diameter } \\
\mathbf{n m}\end{array}$ \\
\hline $100 / 0$ & $102 \pm 10$ & $25.5 \pm 0.9$ & 0.07 & $1360 \pm 521$ \\
\hline $80 / 20$ & $347 \pm 42$ & $27.6 \pm 0.3$ & 1.34 & $557 \pm 176$ \\
\hline $60 / 40$ & $303 \pm 82$ & $30.0 \pm 0.3$ & 2.42 & $272 \pm 58$ \\
\hline $50 / 50$ & $252 \pm 53$ & $30.6 \pm 0.3$ & 2.37 & $316 \pm 69$ \\
\hline $40 / 60$ & $249 \pm 8$ & $32.6 \pm 0.3$ & 3.22 & No \\
\hline $20 / 80$ & $170 \pm 12$ & $35.8 \pm 0.1$ & 3.32 & No \\
\hline $0 / 100$ & $155 \pm 9$ & $38.3 \pm 1.3$ & 3.31 & No \\
\hline
\end{tabular}




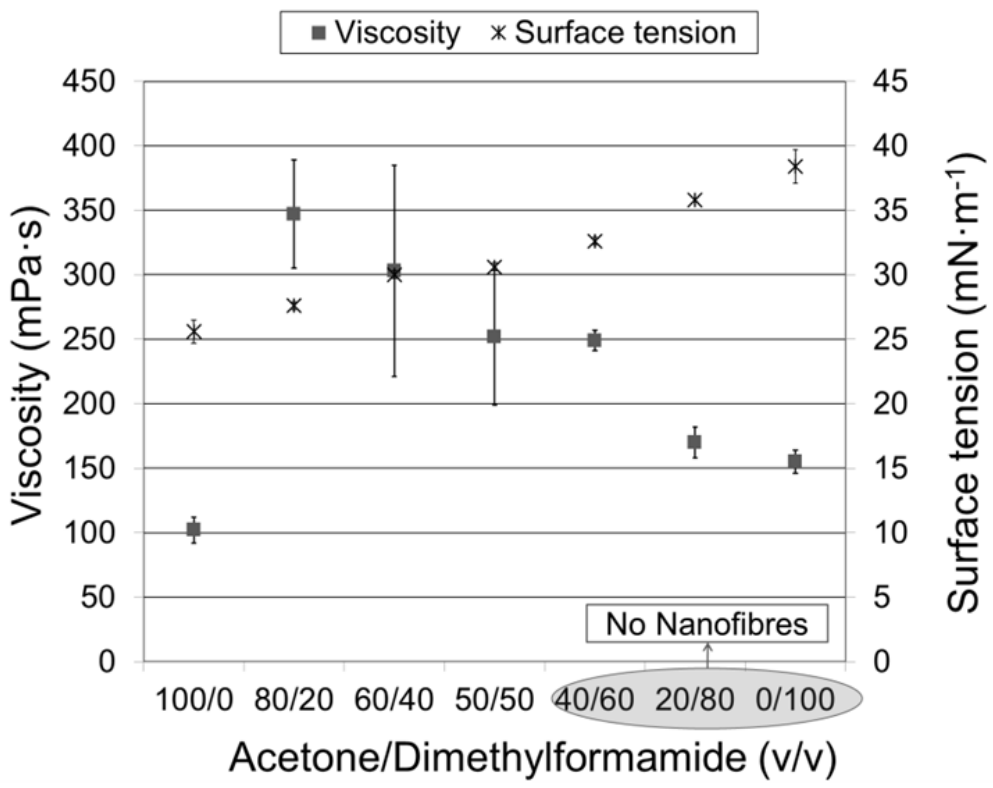

Figure 5. Solution viscosity and surface tension of 10\% PLA solution as a function of the solvent ratio acetone/dimethylformamide (AC/DMF)

\section{Effect of polymer concentration}

The concentration of PLA in the solvent system acetone/dimethylformamide $(50 / 50 \mathrm{v} / \mathrm{v})$ was varied from 5 to $15 \% \mathrm{w} / \mathrm{v}$ in order to study its effect on nanofibre morphology and diameter. All solutions were electrospun using a voltage of $20 \mathrm{kV}$, flow rate $1 \mathrm{ml} / \mathrm{h}$ and over a time span of 10 minutes. The temperature and the relative humidity in the electrospinning chamber were $18^{\circ} \mathrm{C}$ and $47 \%$ respectively. Figure 6 shows selected SEM images of the electrospun nanofibres collected using different polymer concentration.

The results show that few nanofibres with many beads were collected using the $5 \% \mathrm{w} / \mathrm{v}$ PLA solution. The beads formation indicates insufficient chain entanglements. Hence the study was not extended to concentrations below 5\% w/v PLA. On increasing the polymer concentration to $7.5 \% \mathrm{w} / \mathrm{v}$ more nanofibres were produced even though a lot of defects were still present, as shown in Figure 6b. 

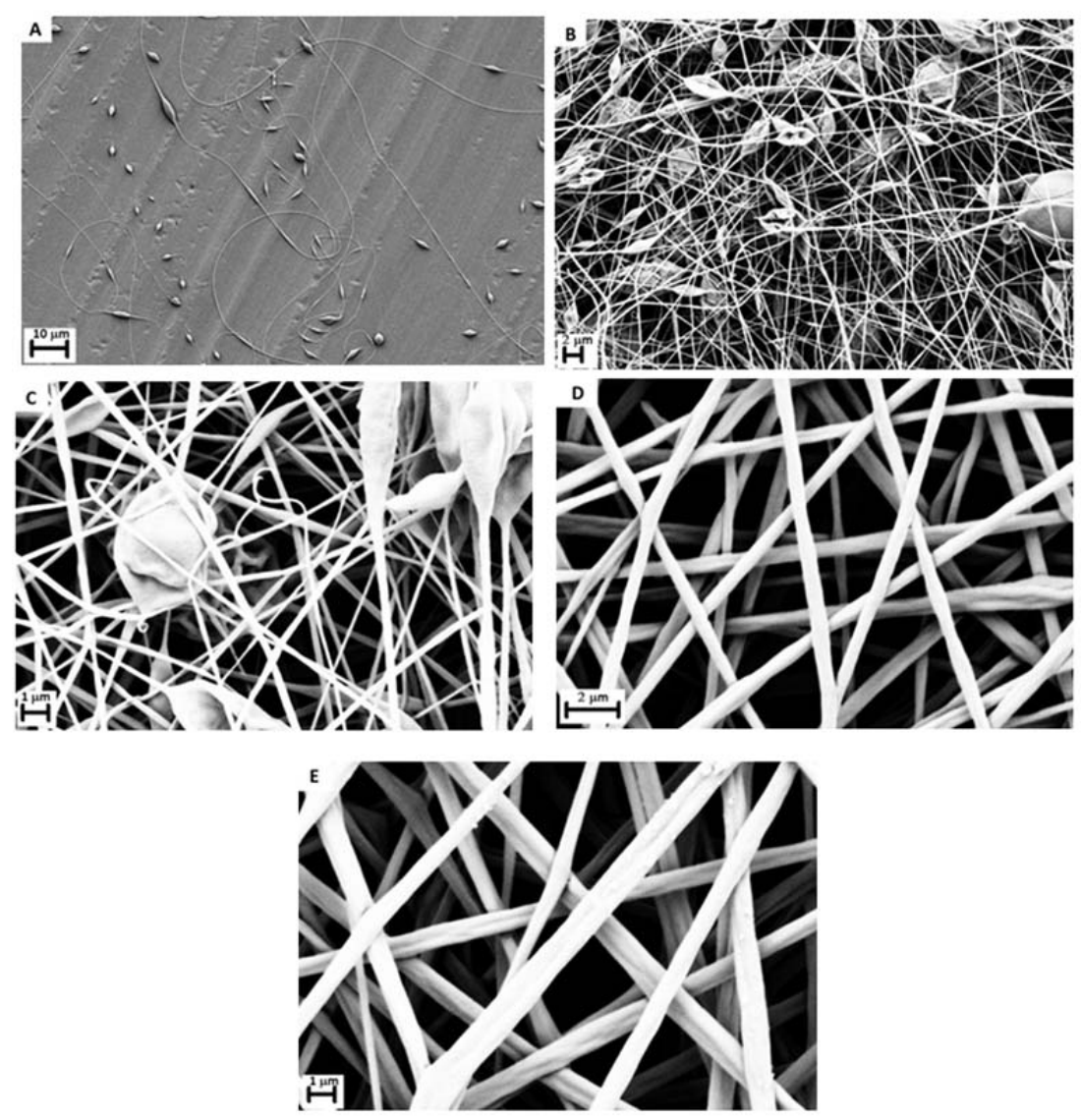

Figure 6. Effect of polymer concentration on nanofibre morphology - scanning electron micrographs of PLA nanofibres from solutions of PLA in acetone/dimethylformamide at a ratio of $50 / 50 \mathrm{v} / \mathrm{v}$ at concentration (a) $5 \% \mathrm{w} / \mathrm{v}(2000 \mathrm{x})$, (b) $7.5 \% \mathrm{w} / \mathrm{v}(5000 \mathrm{x})$, (c) $10 \% \mathrm{w} / \mathrm{v}(15000 \mathrm{x})$, (d) $12.5 \% \mathrm{w} / \mathrm{v}$ (15000x), (e) $15 \% \mathrm{w} / \mathrm{v}(15000 \mathrm{x})$

The PLA nanofibres contained beads up to a concentration of $10 \% \mathrm{w} / \mathrm{v}$. Above $12.5 \% \mathrm{w} / \mathrm{v}$ defect-free fibres could be collected. According to Figure 7, the results show that an increase in the solution concentration clearly results in increased viscosity of the solution. The change in fibre morphology with increasing concentration can be attributed to competition between the surface tension and viscosity. An increase in the polymer concentration results in more chain entanglements, an increase in the solution viscosity, hence an increase in the viscoelastic force which will counterbalance the Coulombic stretching force and therefore resulting in nanofibres with fewer beads $[41,44]$. 
Table 4. Effect of polymer concentration. Effect of PLA concentration on viscosity of PLA solution in acetone/dimethylformamide $(50 / 50 \mathrm{v} / \mathrm{v})$ and mean diameter of nanofibres produced by the electrospinning process

\begin{tabular}{|c|c|c|c|c|}
\hline $\begin{array}{c}\text { PLA } \\
\text { concentration } \\
\mathbf{\%} \mathbf{~ w / v}\end{array}$ & $\begin{array}{c}\text { Solution viscosity } \\
\mathbf{m P a} \cdot \mathbf{s}\end{array}$ & $\begin{array}{c}\text { Surface tension } \\
\mathbf{m N} \cdot \mathbf{m}^{-\mathbf{1}}\end{array}$ & $\begin{array}{c}\text { Conductivity } \\
\boldsymbol{\mu} \mathbf{S} \cdot \mathbf{c m}^{-\mathbf{1}}\end{array}$ & $\begin{array}{c}\text { Mean nanofibre } \\
\text { diameter } \\
\mathbf{n m}\end{array}$ \\
\hline 5 & $22 \pm 9$ & $29.3 \pm 0.3$ & 1.98 & $\begin{array}{c}\text { Few nanofibres, } \\
\text { mainly beads }\end{array}$ \\
\hline 7.5 & $72 \pm 7$ & $29.5 \pm 0.2$ & 2.93 & $223 \pm 57$ \\
\hline 10 & $213 \pm 7$ & $29.0 \pm 0.6$ & 3.40 & $303 \pm 88$ \\
\hline 12.5 & $667 \pm 62$ & $29.6 \pm 0.9$ & 3.87 & $462 \pm 125$ \\
\hline 15 & $1457 \pm 147$ & $29.9 \pm 0.9$ & 3.60 & $685 \pm 206$ \\
\hline
\end{tabular}

Figure 7 shows a $\log / \log$ plot of the concentration dependence of the viscosity for PLA solution in the solvent system acetone/dimethylformamide 50/50 v/v. The results presented were taken at shear rate $1 \mathrm{~s}^{-1}$. Results showed that solution viscosity is proportional to $\mathrm{C}^{0.6}$ up to a concentration of $5.5 \% \mathrm{w} / \mathrm{v}$ and thereafter is proportional to $\mathrm{C}^{4.1}$. The change in slope from 0.6 to 4.1 between 5 and $6 \% \mathrm{w} / \mathrm{v}$ (marked $\mathrm{C}_{\mathrm{e}}$ ) is the boundary between the untangled and entangled regimes. Our results revealed a weaker dependence in the semi dilute unentangled regime compared to the value previously reported [26] for linear polymer in good solvent $\left(\eta_{\mathrm{sp}} \sim \mathrm{C}^{1.25}\right)$, probably due to the fact that we used a binary solvent system (AC/DMF). However the semi dilute entangled regime $\eta_{\mathrm{sp}} \sim \mathrm{C}^{4.1}$ is in good agreement with the theoretical value $\left(\eta_{\mathrm{sp}} \sim \mathrm{C}^{4.25-4.5}\right)$.

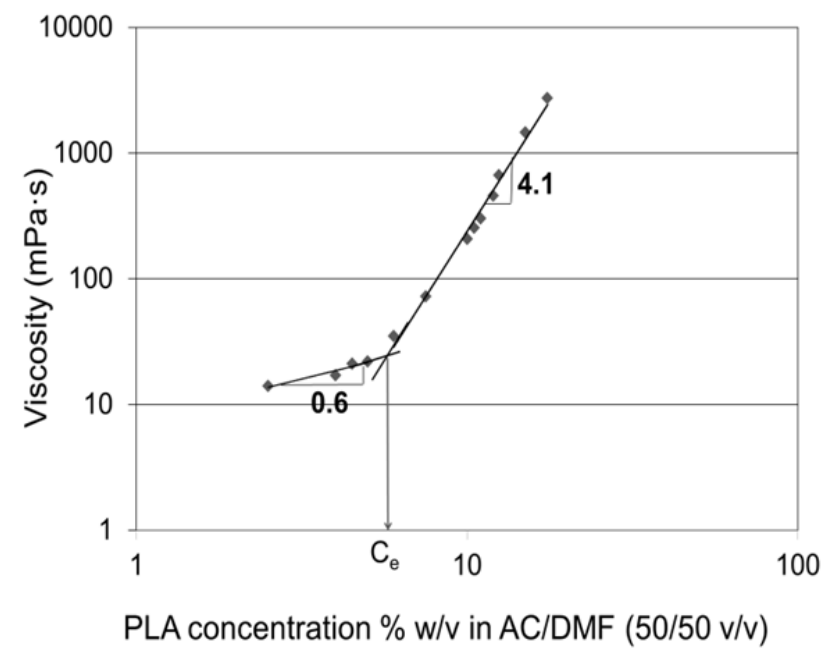

Figure 7. Effect of PLA concentration on viscosity of PLA solution in acetone/dimethylformamide $(50 / 50 \mathrm{v} / \mathrm{v})$ 


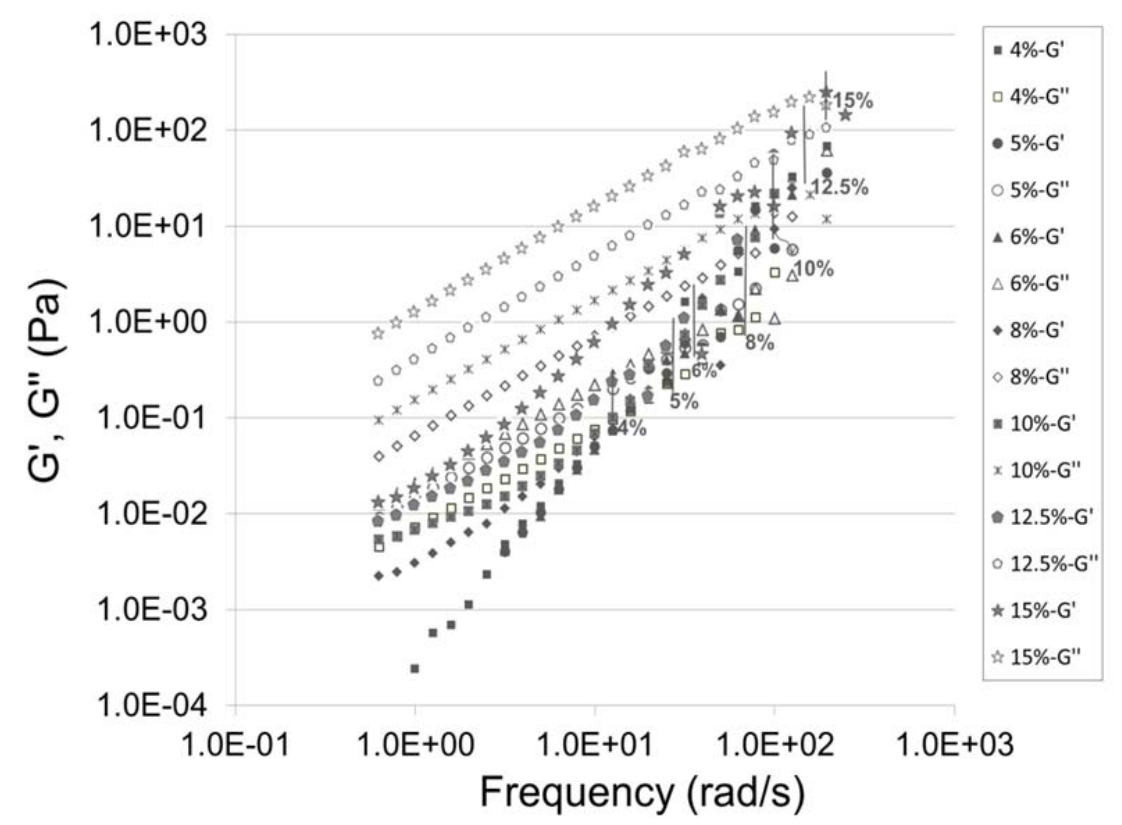

Figure 8. Frequency dependence of elastic (G') and plastic (G') modulus of PLA solution in acetone/dimethylformamide $(50 / 50 \mathrm{v} / \mathrm{v})$ at different PLA concentration

The results from oscillatory measurements for different PLA solution concentration are shown in Figure 8. The plasticity of the system for all solutions is always higher than the elasticity of the system. From Figure 9 a change in slope is clearly visible for the values of elastic modulus $\mathrm{G}^{\prime}$ at a PLA concentration of about $6 \% \mathrm{w} / \mathrm{v}$ at all three frequencies chosen. This can be attributed to chain entanglements and is predicted to give rise to a change in nanofibre morphology. The elastic modulus $G^{\prime}$ is proportional to $C^{3.1}$ for all frequencies. Moreover it was found that the overlap frequency $\omega c$ at which $G^{\prime}$ overcome $G$ ', increases with increasing PLA concentration from $2.5 \mathrm{~Hz}(4 \% \mathrm{w} / \mathrm{v})$ to $31 \mathrm{~Hz}(15 \%)$. Chisca et al [28] electrospun aromatic polyimide solutions in dimethylacetamide and from oscillatory rheometry measurements they found that $\omega \mathrm{c}$ increased with decreasing solution concentration. Most likely the opposite relationship between the concentration and the crossover frequency is due to the different polymeric solution system. Therefore, for comparison, we prepared PLA solution in acetone at 1,5 and $10 \% \mathrm{w} / \mathrm{v}$ polymer concentration and repeated the oscillatory measurements. We found that the crossover point shift to a lower frequency as the solution concentration increased, as shown in Figure 10. From the analysis of the morphology in the FEG-SEM as shown in Figure 6 and the viscosity measurements as shown in Figure 7 this change entanglements occurs between 5.5 and $6 \% \mathrm{w} / \mathrm{v}$ PLA concentration. Moreover it is seen from Figure $6(\mathrm{~d})$ that defect-free nanofibres are formed at twice the chain entanglement concentration $\left(2 \mathrm{C}_{\mathrm{e}}\right)$. 


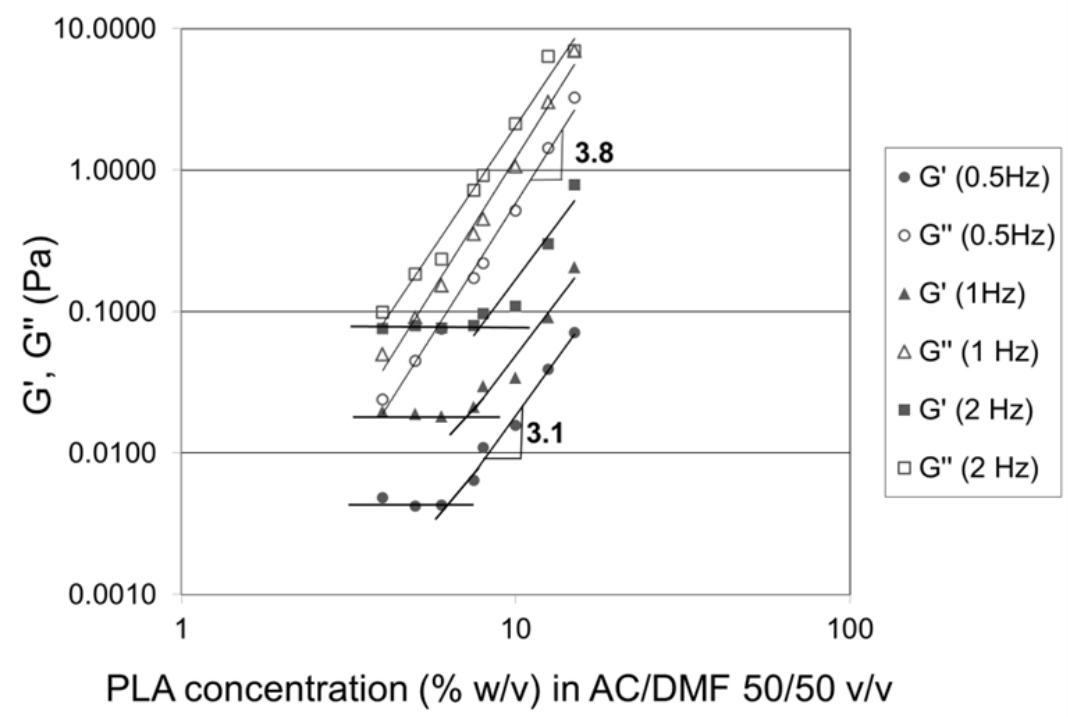

Figure 9. Effect of PLA concentration in acetone/dimethylformamide $(50 / 50 \mathrm{v} / \mathrm{v})$ on the elastic $\left(G^{\prime}\right)$ and plastic $(G$ ') modulus at $0.5,1$ and $2 \mathrm{~Hz}$

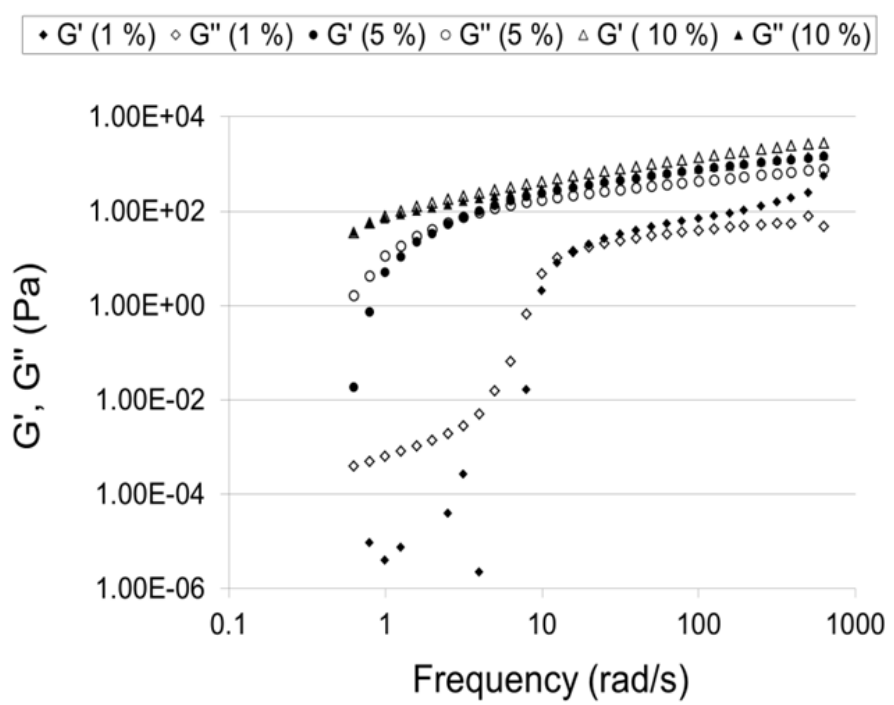

Figure 10. Frequency dependence of elastic (G') and plastic (G') modulus of PLA/acetone solution at different PLA concentration 


\section{Conclusions}

In the present study, electrospinning was used to produce PLA nanofibres from PLA solution in various solvents and binary-solvent systems. The main objective was to study the effect of different solvent systems on the PLA nanofibre diameter and morphology. Moreover different polymer concentrations in the most promising solvent system were utilized to further explore the relationship between viscosity and concentration and investigate its impact on the fibre formation.

Among the PLA-solutions in single solvents, only the PLA solution in $10 \% \mathrm{w} / \mathrm{v}$ acetone produced PLA nanofibres. Therefore binary solvent systems were based on mixtures of acetone and another solvent. All the PLA solutions in binary solvent systems of $10 \% \mathrm{w} / \mathrm{v}$ were spinnable and nanofibres could be collected. The effect of different binary solvent systems on nanofibre morphology and diameter was observed by scanning electron microscopy (SEM).

Results showed that beaded nanofibres were collected using the solvent systems acetone/1,4dioxane, acetone/tetrahydrofuran, acetone/dichloromethane and acetone/chloroform, while defect-free nanofibres were collected using the solvent systems acetone/dimethylformamide and acetone/dimethylacetamide. This is probably due to the higher electrical conductivity of the resulting PLA solution. Moreover among the binary solvent systems it was found that the mean nanofibre diameter decreased as the boiling point of the second solvent in the binarysolvent system increased.

The effect of different solvent ratios of acetone/dimethylformamide (AC/DMF) on nanofibre morphology and diameter was also investigated. Thinner nanofibres with a narrow diameter distribution were produced using the solvent ratio 60/40 v/v. On increasing the amount of acetone in the solvent system defect-free nanofibre could be produced but the mean nanofibre diameter was found to increase.

The PLA concentration was also varied using the solvent system AC/DMF at ratio 50/50 v/v to investigate the effect on solution viscosity and nanofibre diameter. Above $12.5 \% \mathrm{w} / \mathrm{v}$ PLA concentration uniform defect-free nanofibres could be produced. Hence the chain entanglement concentration, $\mathrm{C}_{\mathrm{e}}$, was taken as $5.5 \% \mathrm{w} / \mathrm{v}$. This corresponds to the concentration at which nanofibres are first observed. Also rotational and oscillatory tests revealed a chain entanglement concentration $\left(\mathrm{C}_{\mathrm{e}}\right)$ of approximately $6 \% \mathrm{w} / \mathrm{v}$ and beaded nanofibres were collected. 


\section{References}

[1] Gibson H.L., Gibson P., Tsai P., Gupta P. WG. Cooperative charging effects of fibers from electrospinning of electrically dissimilar polymers. INJ Winter 2004:39-45.

[2] Wang X, Kim Y-G, Drew C, Ku B-C, Kumar J, Samuelson LA. Electrostatic assembly of conjugated polymer thin layers on electrospun nanofibrous membranes for biosensors. Nano Letters 2004;4:331-4.

[3] Agarwal S, Wendorff JH, Greiner A. Use of electrospinning technique for biomedical applications. Polymer 2008;49:5603-21.

[4] Kanani AG, Bahrami SH. Review on electrospun nanofibers scaffold and biomedical applications. Trends Biomaterial Artificial Organs 2010;24:93-115.

[5] Yang F, Murugan R, Wang S, Ramakrishna S. Electrospinning of nano/micro scale poly(L-lactic acid) aligned fibers and their potential in neural tissue engineering. Biomaterials 2005;26:2603-10.

[6] Khil M, Cha D, Kim H, Kim I, Bhattarai N. Electrospun nanofibrous polyurethane membrane as wound dressing. Journal of Biomedical Materials Research Part B Applied Biomaterial 2003;67:675-9.

[7] Kenawy E-R, Bowlin GL, Mansfield K, Layman J, Simpson DG, Sanders EH, et al. Release of tetracycline hydrochloride from electrospun poly(ethylene-co-vinylacetate), poly(lactic acid), and a blend. Journal of Controlled Release : Official Journal of the Controlled Release Society 2002;81:57-64.

[8] Doshi J, Reneker DH. Electrospinning process and applications of electrospun fibers. Journal of Electrostatics 1995;35:151-60.

[9] Reneker DH, Yarin A, Zussman E, Xu H. Electrospinning of nanofibers from polymer solutions and melts. Advances in Applied Mechanics 2007;41:44-195.

[10] Theron SA, Zussman E, Yarin AL. Experimental investigation of the governing parameters in the electrospinning of polymer solutions. Polymer 2004;45:2017-30.

[11] De Vrieze S, Camp T, Nelvig A, Hagström B, Westbroek P, Clerck K. The effect of temperature and humidity on electrospinning. Journal of Materials Science 2008;44:1357-62.

[12] Kim G-T, Lee J-S, Shin J-H, Ahn Y-C, Hwang Y-J, Shin H-S, et al. Investigation of pore formation for polystyrene electrospun fiber: effect of relative humidity. Korean J Chem Eng 2005;22:783-8.

[13] Fong H, Chun I, Reneker D. Beaded nanofibers formed during electrospinning. Polymer 1999;40:4585-92. 
[14] Wannatong L, Sirivat A, Supaphol P. Effects of solvents on electrospun polymeric fibers: preliminary study on polystyrene. Polymer International 2004;53:1851-9.

[15] Lee KH, Kim HY, Khil MS, Ra YM, Lee DR. Characterization of nano-structured poly(-caprolactone) nonwoven mats. Polymer Journal 2003;44:1287-94.

[16] Lee KH, Kim HY, La YM, Lee DR, Sung NH. Influence of a mixing solvent with tetrahydrofuran andN,N-dimethylformamide on electrospun poly(vinyl chloride) nonwoven mats. Journal of Polymer Science Part B: Polymer Physics 2002;40:225968.

[17] Gu S-Y, Ren J. Process optimization and empirical modeling for electrospun poly(D,L-lactide) fibers using response surface methodology. Macromolecular Materials and Engineering 2005;290:1097-105.

[18] Patra SN, Easteal a. J, Bhattacharyya D. Parametric study of manufacturing poly(lactic) acid nanofibrous mat by electrospinning. Journal of Materials Science 2008;44:647-54.

[19] Yang F, Xu CY, Kotaki M, Wang S, Ramakrishna S. Characterization of neural stem cells on electrospun poly(L-lactic acid) nanofibrous scaffold. Journal of Biomaterials Science Polymer Edition 2004;15:1483-97.

[20] Prabhakaran MP, Ghasemi-Mobarakeh L, Jin G, Ramakrishna S. Electrospun conducting polymer nanofibers and electrical stimulation of nerve stem cells. Journal of Bioscience and Bioengineering 2011;112:501-7.

[21] Ishii D, Ying TH, Mahara A, Murakami S, Yamaoka T, Lee W, et al. In vivo tissue response and degradation behavior of PLLA and stereocomplexed PLA nanofibers. Biomacromolecules 2009;10:237-42.

[22] Van der Schueren L, De Schoenmaker B, Kalaoglu ÖI, De Clerck K. An alternative solvent system for the steady state electrospinning of polycaprolactone. European Polymer Journal 2011;47:1256-63.

[23] Jarusuwannapoom T, Hongrojjanawiwat W, Jitjaicham S, Wannatong L, Nithitanakul M, Pattamaprom C, et al. Effect of solvents on electro-spinnability of polystyrene solutions and morphological appearance of resulting electrospun polystyrene fibers. European Polymer Journal 2005;41:409-21.

[24] Eda G, Liu J, Shivkumar S. Solvent effects on jet evolution during electrospinning of semi-dilute polystyrene solutions. European Polymer Journal 2007;43:1154-67.

[25] McKee MG, Wilkes GL, Colby RH, Long TE. Correlations of solution rheology with electrospun fiber formation of linear and branched polyesters. Macromolecules 2004;37:1760-7.

[26] Colby RH, Fetters LJ, Funk WG, J WWG. Effects of concentration and thermodynamic interaction on the viscoelastic properties of polymer solutions. Macromolecules 1991;24:3873-82. 
[27] Supaphol P, Mit-uppatham C, Nithitanakul M. Ultrafine electrospun polyamide-6 fibers: effects of solvent system and emitting electrode polarity on morphology and average fiber diameter. Macromolecular Materials and Engineering 2005;290:933-42.

[28] Chisca S, Barzic AI, Sava I, Olaru N, Bruma M. Morphological and rheological insights on polyimide chain entanglements for electrospinning produced fibers. The Journal of Physical Chemistry B 2012;116:9082-8.

[29] Tang C, Saquing CD, Harding JR, Khan SA. In situ cross-linking of electrospun poly(vinyl alcohol) nanofibers. Macromolecules 2010;43:630-7.

[30] Liu H, Hsieh Y-L. Ultrafine fibrous cellulose membranes from electrospinning of cellulose acetate. Journal of Polymer Science Part B: Polymer Physics 2002;40:2119_ 29.

[31] Tiwari SK, Venkatraman SS. Importance of viscosity parameters in electrospinning: Of monolithic and core-shell fibers. Materials Science and Engineering: C 2012;32:1037-42.

[32] Bonino CA, Krebs MD, Saquing CD, Jeong SI, Shearer KL, Alsberg E, et al. Electrospinning alginate-based nanofibers: From blends to crosslinked low molecular weight alginate-only systems. Carbohydrate Polymers 2011;85:111-9.

[33] Rošic R, Pelipenko J, Kocbek P, Baumgartner S, Bešter-Rogač M, Kristl J. The role of rheology of polymer solutions in predicting nanofiber formation by electrospinning. European Polymer Journal 2012;48:1374-84.

[34] Regev O, Vandebril S, Zussman E, Clasen C. The role of interfacial viscoelasticity in the stabilization of an electrospun jet. Polymer 2010;51:2611-20.

[35] Yu JH, Fridrikh S V., Rutledge GC. The role of elasticity in the formation of electrospun fibers. Polymer 2006;47:4789-97.

[36] Xiao L, Wang B, Yang G, Gauthier M. Poly (lactic acid)-based biomaterials: synthesis , modification and applications. Biomedical Science, Engineering and Technology 2012:247-82.

[37] Lim L-T, Auras R, Rubino M. Processing technologies for poly(lactic acid). Progress in Polymer Science 2008;33:820-52.

[38] Garlotta D. A literature review of poly (lactic acid). Journal of Polymers and the Environment 2002;9:63-84.

[39] Yang Y, Jia Z, Li Q, Guan Z. Experimental investigation of the governing parameters in the electrospinning of polyethylene oxide solution. IEEE Transactions on Dielectrics and Electrical Insulation 2006;13:580-5.

[40] Hohman MM, Shin M, Rutledge G, Brenner MP. Electrospinning and electrically forced jets. I. Stability theory. Physics of Fluids 2001;13:2201. 
[41] Jun Z, Hou H, Schaper A, Wendorff JH, Greiner A. Poly-L-lactide nanofibers by electrospinning - Influence of solution viscosity and electrical conductivity on fiber diameter and fiber morphology. E-Polymers 2003;3:102-10.

[42] Hohman MM, Shin M, Rutledge G, Brenner MP. Electrospinning and electrically forced jets. II. Applications. Physics of Fluids 2001;13:2221.

[43] Zhang C, Yuan X, Wu L, Han Y, Sheng J. Study on morphology of electrospun poly(vinyl alcohol) mats. European Polymer Journal 2005;41:423-32.

[44] Zong X, Kim K, Fang D, Ran S, Hsiao BS, Chu B. Structure and process relationship of electrospun bioabsorbable nanofiber membranes. Polymer 2002;43:4403-12. 